\title{
Bilateral Medial Medullary Infarction (Dejerene Syndrome) Patient Suffering from Quadriplegia Treated by Korean Traditional Medicine: a Case Report
}

\author{
Yoo-na Lee, Yu-min An, Kyungmin Baek, Woo-seok Jang \\ Dept. of Cardiovascular and Neurologic Diseases of Korean Internal Medicine, \\ Daegu Korean Medical Hospital of Daegu Haany University
}

\section{Bilateral Medial Medullary Infarction (Dejerene Syndrome) Patient Suffering from Quadriplegia Treated by Korean Traditional Medicine: a Case Report}

\author{
Yoo-na Lee, Yu-min An, Kyungmin Baek, Woo-seok Jang \\ Dept. of Cardiovascular and Neurologic Diseases of Korean Internal Medicine, \\ Daegu Korean Medical Hospital of Daegu Haany University
}

\begin{abstract}
Medial medullary infarction, with representing symptoms of hemiparesis, lingual palsy, and sensory defect, usually has a bad prognosis. The present case is unusual as the patient had a bilateral infarction, and little information is available for bilateral cases. We treated a patient diagnosed with bilateral medial medullary infarction with the symptoms of quadriplegia, lingual palsy, dyspnea, dysphagia, spastic pain, and loss of proprioception. After 126 days of traditional Korean medicine treatment, the patient showed increased muscle power, sensory recovery, reduced spastic pain, and alleviation of dysphagia and dyspnea. This report indicates that traditional Korean medicine could be an effective treatment of the sequelae of medullary infarctions.
\end{abstract}

$\overline{\text { Key words: }}$ stroke, quadriplegia, medial meudllary syndrome, Korean traditional medicine

\section{Introduction}

Medulla oblongata, a part of brain stem, consists of many nuclei. It is an important entrance and

· 투고일: 2020.09.24, 심사일: 2020.10.30, 게재확정일: 2020.10 .30

- Corresponding author: Woo-seok Jang Dept. of Cardiovascular and Neurologic Diseases of Korean Internal Medicine, Daegu Korean Medical Hospital of Daegu Haany University, 136 Shincheon -dong-ro, Suseong-gu, Daegu, South Korea TEL: 053-770-2125 FAX: 053-770-2055 E-mail: freesoso1@naver.com exit of central-peripheral nervous system. 1 . It functions as vital organ that regulates consciousness and respiratory system. Its blood supply depends on posterior circulatory system and is divided as medial and lateral part according to vascular distribution ${ }^{2.3}$. The medial medullary infarction, called as Dejerine syndrome, is an outcome of vertebral artery occlusion. Injury of pyramidal nucleus may result in contralateral hemiparesis, and medial lemniscus damage results in impairment of vibration and positioning sense ${ }^{3,4}$. 
Cerebral infarction of the posterior circulatory system has a higher probability of worsening symptoms after onset or accompanying coma than that of anterior circulatory system. The worsening rate of symptoms in the acute phase is $46 \%$ within 48 hours of onset, requiring emergent treatment ${ }^{5}$. However, due to its rarity, studies about medial medullary infarction are insufficient. It is very unlikely that medial medullary infarction, which has a low incidence of $0.5-1.5 \%$ of all cerebral infarctions ${ }^{1,6}$, to occur bilaterally. Domestically, there is only one case $^{7}$ reported and none about traditional Korean medicine (TKM) treatment for bilateral medial medullary infarction. Compared to the severity of the disease, more studies are required. Therefore, we report a case of bilateral medial medullary infarction treated with TKM.

\section{Case report}

A 55-year-old man, with past history of hyperlipidemia and diabetes mellitus, felt severe headache and dizziness while driving. He was a heavy smoker and drinker. He immediately drived to emergency room and had the brain magnetic resonance imaging (brain MRI) scan. There were suspicious findings of brain infarction, but the MRI couldn't specify the exact part. Although he had received antiplatelet therapy and hydration, next day the symptom developed to quadriplegia (Manual Muscle Test (MMT) grade 1). So he was transferred to the other hospital, and was diagnosed with bilateral medial medullary infarction, exhibiting the "heart appearance" sign after the second brain MRI scan. The occlusion of left internal carotid artery left middle cerebral artery and right vertebral artery was revealed by magnetic resonance angiography
(MRA) (Fig. 1). After admission, severe dysphagia, aspiration pneumonia and urinary tract infection (UTI) was found out so he had to insert levin tube, foley catheter, receive tracheostomy and 02 inhalation. After 17 days from the onset, the levin tube was removed and the percutaneous endoscopic gastrostomy (PEG) was done. There was no improvement of the symptoms after total 45 days of admission, and he visited our clinic to receive traditional Korean medicine treatment.

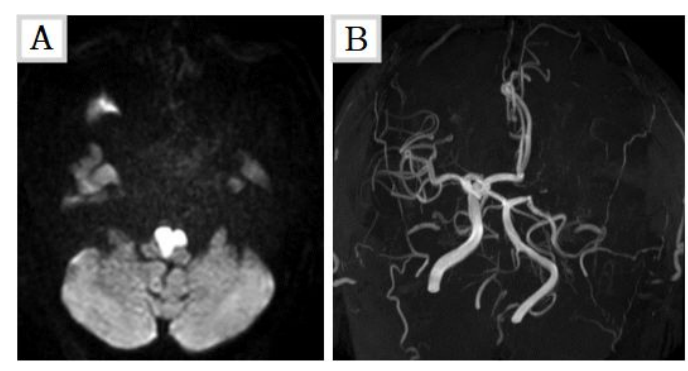

Fig. 1. Images of brain magnetic resonance imaging.

It was scanned 7 days after the onset. (A) DWI (diffusion weighted imaging) shows high signal in bilateral medullary area. (B) MRA (magnetic resonance angiography) shows occlusion of left internal carotid artery, left middle cerebral artery and right vertebral artery.

He was on dual antiplatelet therapy (clopidogrel $75 \mathrm{mg}$ once a day, cilostazol $100 \mathrm{mg}$ twice a day) and lipid-lowering drug (atorvastatin $20 \mathrm{mg}$ once a day). To control high blood pressure and glucose level, diltiazem $30 \mathrm{mg}$ and metformin $1000 \mathrm{mg}$, each twice a day, were prescribed. He also was medicated with an expectorant (acetylcysteine $200 \mathrm{mg}$ twice a day), benzodiazepine (escitalopram $10 \mathrm{mg}$ once a day), selective serotonin reuptake inhibitor (Alprazolam $0.25 \mathrm{mg}$ twice a day) and antipeptic ulcer drug (rebamipide $100 \mathrm{mg}$ three times a day) to treat aspiration bronchitis, anxiety neurosis and to 
Bilateral Medial Medullary Infarction (Dejerene Syndrome) Patient Suffering from Quadriplegia

Treated by Korean Traditional Medicine: a Case Report

prevent gastrointestinal bleeding.

On admission, his vital signs were relatively unstable. High blood pressure (160/90 mmHg), tachycardia (106 times per minute), tachypnea (22 times per minute) and slight fever $\left(37.3{ }^{\circ} \mathrm{C}\right)$ were recorded. Chest X-rays showed mild cephalization of pulmonary vasculature, and the laboratory findings suggested an infectious state (white blood cell (WBC) $10700 / \mu \mathrm{L}$, neutrophil $81 \%$, lymphocyte $12 \%$, erythrocyte sedimentation rate $41 \mathrm{~mm} / \mathrm{h}$ in blood and many WBC in urine). He had severe quadriplegia, whole four limbs scoring grade 1, by MMT. Lingual palsy, loss of proprioception, diplopia, dysphagia, atrophy, spasticity and hyperactive state of biceps $\&$ triceps deep tendon reflex were observed. As he had difficulty in breathing himself, tracheal tube was kept inserted and oxygen inhalation had to be done daily. The patient also complained of pain in whole body, sputum, dysuria and diarrhea. Considering tachycardia (脈滑數), reddish-tip of tongue (舌尖 紅) and dysuria (小便赤涉), he was diagnosed as fire-heat (火熱) and lung-heat injury (肺熱傷津) pattern of TKM terms. Due to severe spasticity of whole upper and lower extremities, the patient complained of unbearable pain. There were many difficulties in rehabilitation because of limited movement. The electro-acupuncture (EA) treatment has been done to deal with these problems, in acupoints of baihui (GV20), hegu (LI4), neiguan
(PC6), waiguan (TE5), jian yu (LI15), qu chi (LI11), feng shi (GB31) and yang ling quan (GB34). Moxibustion, cupping and physical treatment were additionally prescribed. Also, herbal therapy has been done to treat his infectious problems, cardiovascular problems and help neuroplasticity.

In order to evaluate the treatment effects, MMT, National Institutes of Health Stroke Scale (NIHSS), Numeric Rating Scale-11 (NRS-11) and percentage (\%) had been applied. After treatment, quadriplegia was ameliorated from MMT grade 1 to grade 2-3 (Table 1). NRS-11 was used to evaluate the limb pain. NRS 10 meant the most painful state, and NRS 0 meant that there was no pain. Also, as the patient had excessive sputum production, the percentage was used to evaluate the subjective discomfort caused by sputum discharge. The degree of discomfort on admission day was recorded as 100\%, and the change of symptom was relatively measured. NIHSS score declined to 12, compared to 18 on the admission (Table 2). Limb pain also was alleviated, scoring from NRS 10 to NRS 2 on discharge day (Fig. 2). Sputum had decreased from 100\% to 20\% (Fig. 3). 7 days before discharge, tracheal tube was removed and he had no need to receive oxygen supply anymore. 118 days after admission, recovery of proprioception was observed. 
Table 1. The Change of Manual Muscle Test

\begin{tabular}{|c|c|c|c|c|c|c|}
\hline & $\begin{array}{l}\text { Admission } \\
\text { day }\end{array}$ & 7th day & 39th day & 60th day & 85th day & $\begin{array}{c}\text { 126th day } \\
\text { (discharge } \\
\text { day) }\end{array}$ \\
\hline Shoulder & 1/1（Rt.） & 1/1（Rt.） & 1/1 (Rt.) & 1/1 (Rt.) & 2/2（Rt.） & $2+/ 2$ (Rt.) \\
\hline abduction/adduction & 1/1 (Lt.) & 1/1 (Lt.) & 1/1 (Lt.) & 1/1 (Lt.) & 2/2 (Lt.) & 2/2 (Lt.) \\
\hline Elbow & 1/1 (Rt.) & 2/2 (Rt.) & $2+/ 2$ (Rt.) & 3/2 (Rt.) & $3+/ 3$ (Rt.) & $3+/ 3$ (Rt.) \\
\hline flexion/extension & 1/1 (Lt.) & 2/2 (Lt.) & $2+/ 2$ (Lt.) & 3/2 (Lt.) & $3+/ 3$ (Lt.) & 3+/3 (Lt.) \\
\hline Wrist & 1/1 (Rt.) & 2/2 (Rt.) & $2 / 2$ (Rt.) & 2/2 (Rt.) & 3/3 (Rt.) & 3/3 (Rt.) \\
\hline dorsi flexion/plantar flexion & 1/1 (Lt.) & 2/2 (Lt.) & 2/2 (Lt.) & 2/2 (Lt.) & 3/3 (Lt.) & 3/3 (Lt.) \\
\hline Finger & 1/1 (Rt.) & 2/2 (Rt.) & $3+/ 3$ (Rt.) & $3+/ 3$ (Rt.) & $3+/ 3$ (Rt.) & $3+/ 3$ (Rt.) \\
\hline flexion/extension & 1/1 (Lt.) & 2/2 (Lt.) & $3+/ 3$ (Lt.) & $3+/ 3$ (Lt.) & $3+/ 3$ (Lt.) & $3+/ 3$ (Lt.) \\
\hline Hip & $1 / 1$ (Rt.) & 2/1 (Rt.) & 2/1 (Rt.) & 2/1 (Rt.) & $2+/ 2$ (Rt.) & $2+/ 2$ (Rt.) \\
\hline abduction/adduction & 1/1 (Lt.) & 2/1 (Lt.) & 2/1 (Lt.) & 2/1 (Lt.) & 2/1 (Lt.) & 2/1 (Lt.) \\
\hline Knee & 1/1 (Rt.) & 2/2 (Rt.) & $2+/ 2$ (Rt.) & $2+/ 2$ (Rt.) & $2+/ 2$ (Rt.) & $2+/ 2$ (Rt.) \\
\hline flexion/extension & 1/1 (Lt.) & 2/2 (Lt.) & $2+/ 2$ (Lt.) & $2+/ 2$ (Lt.) & $2+/ 2$ (Lt.) & $2+/ 2$ (Lt.) \\
\hline Ankle & $1 / 1$ (Rt.) & $1 / 2$ (Rt.) & $1 / 2$ (Rt.) & $1 / 2(\mathrm{Rt})$. & $1 / 2(\mathrm{Rt})$. & $1 / 2(\mathrm{Rt})$. \\
\hline dorsi flexion/plantar flexion & 1/1 (Lt.) & 2/2 (Lt.) & 2/2 (Lt.) & 2/2 (Lt.) & 2/2 (Lt.) & 2/2 (Lt.) \\
\hline Toe & 1/1 (Rt.) & 2/2 (Rt.) & 2/2 (Rt.) & 3/2 (Rt.) & 3/2 (Rt.) & 3/2 (Rt.) \\
\hline flexion/extension & 1/1 (Lt.) & 2/2 (Lt.) & 2/2 (Lt.) & 3/2 (Lt.) & 3/2 (Lt.) & 3/2 (Lt.) \\
\hline
\end{tabular}

Table 2. The Change of National Institutes of Health Stroke Scale from the Admission to Discharge Day

\begin{tabular}{lcc} 
& Admission day & Discharge day \\
\hline 1a. Level of consciousness & $0 / 3$ & $0 / 3$ \\
\hline 1b. LOC questions & $1 / 2$ & $0 / 2$ \\
\hline 1.. LOC commands & $0 / 2$ & $0 / 2$ \\
\hline 2. Best gaze & $0 / 2$ & $0 / 2$ \\
\hline 3. Visual & $0 / 3$ & $0 / 3$ \\
\hline 4. Facial palsy & $0 / 3$ & $0 / 3$ \\
\hline 5a. Motor arm (Rt.) & $4 / 4$ & $3 / 4$ \\
\hline 5b. Motor arm (Lt.) & $4 / 4$ & $3 / 4$ \\
\hline 6a. Motor leg (Rt.) & $4 / 4$ & $3 / 4$ \\
\hline 6b. Motor leg (Lt.) & $4 / 4$ & $3 / 4$ \\
\hline 7. Limb ataxia & $0 / 2$ & $0 / 2$ \\
\hline 8. Sensory & $1 / 2$ & $0 / 2$ \\
\hline 9. Best language & $0 / 3$ & $0 / 3$ \\
\hline 10. Dysarthria & Untestable (T-tube inserted state) & $0 / 2$ \\
\hline 11. Extinction and inattention & $0 / 2$ & $0 / 2$ \\
\hline
\end{tabular}


Bilateral Medial Medullary Infarction (Dejerene Syndrome) Patient Suffering from Quadriplegia Treated by Korean Traditional Medicine: a Case Report

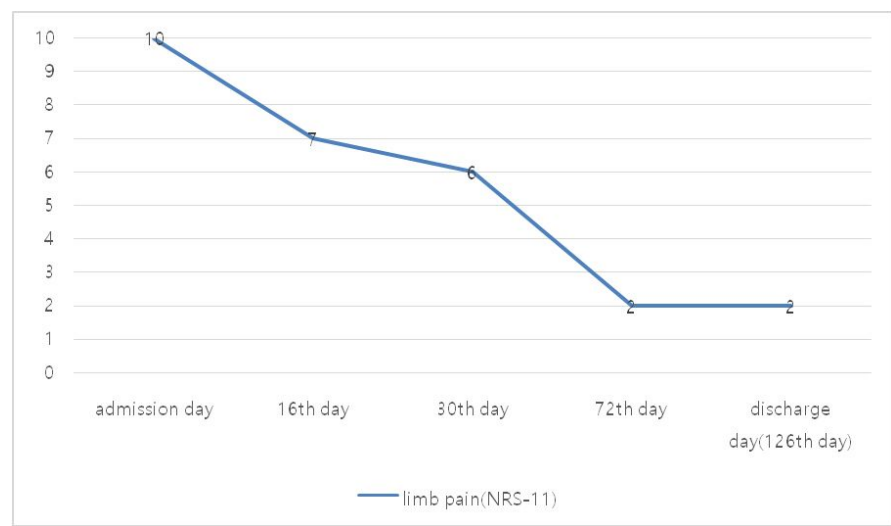

Fig. 2. The change of numeric rating scale-11, showing progress of limb pain.

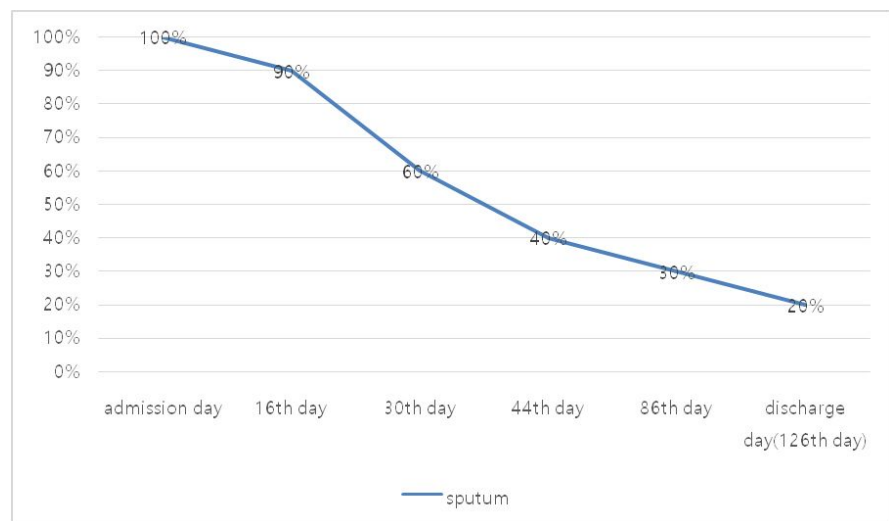

Fig. 3. The change of percentage, showing subjective discomfort caused by sputum.

To cope with infectious state of admission day, with mild fever $\left(37.3{ }^{\circ} \mathrm{C}\right)$ and abnormal WBC count (WBC 10700/ $\mathrm{LL}$, neutrophil 81\%), modified Chai Ling-tang (柴苓湯 加味方) and antibiotic (amoxicillin/clavulanic acid potassium $375 \mathrm{mg}$ three times per day) were prescribed for six days. A day after medication WBC count has decreased to $7500 / \mu \mathrm{L}$ and neutrophil $78 \%$. Urine WBC was many, but body temperature (BT) has returned to normal range $\left(36.5{ }^{\circ} \mathrm{C}\right)$. Five days after medication, vital signs kept stable state and urine WBC has decreased to 20-29/HPF, so no more antibiotic was prescribed, and the herbal decoction has changed to modified Fen Xinqi-yin (分心氣飲 加味方) to treat pulmonary problems by lessening cardiac load. However, on the 13th day of admission, BT elevated up to $39.4{ }^{\circ} \mathrm{C}$, and the laboratory findings

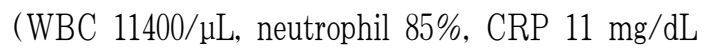
and urine WBC many) implied recurrence of UTI. Modified Chai Ling-tang (柴苓湯 加味方) for 18 days and amoxicillin/clavulanic acid potassium $375 \mathrm{mg}$ three times per day, for 8 days, was medicated again. Fever has been removed on the second day of prescription, and the infection has been alleviated

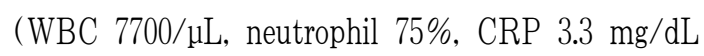
and urine WBC 10-19/HPF). As a consequence of 
long-time struggle with infection, the patient went exhausted, so modified Liu Wei Dihuang-tang (六 味地黃湯 加味方) and modified Jing Fang Di Huang-tang（荊防地黄湯 加味方） were prescribed, sequently. The treatment showed a good result, with observation of MMT increase. Expecting more recovery of neurological deficits, modified Bu Yang Huan Wu-tang (補陽還五湯 加味方) was prescribed on 50th day, but we had to change prescription to modified Chai Ling-tang (柴苓湯 加味方) because UTI had recurred (BT $37.4{ }^{\circ} \mathrm{C}$, WBC 10200/ $\mu \mathrm{L}$, neutrophil $74.4 \%$, CRP $9.8 \mathrm{mg} / \mathrm{dL}$, and urine $\mathrm{WBC}$ many). This time, only TKM treatment had been done, without prescription of antibiotics. After 5 days,
UTI was alleviated (WBC 7400, neutrophil $67.7 \%$, CRP $0.3 \mathrm{mg} / \mathrm{dL}$ and urine WBC 30-35/HPF). As vital signs became stable, the patient was medicated with modified Bu Yang Huan Wu-tang (補陽還五 湯 加味方) again. Within 36 days of medication, considerable increase of MMT has been observed. To supplement yin-deficiency, medication has changed to modified Jing Fang Di Huang-tang (荊防地黄湯 加味方), on 96th day of admission. On 121th day, modified Chai Ling-tang (柴苓湯 加味方) was prescribed because of slight fever $\left(37.4{ }^{\circ} \mathrm{C}\right)$, and it was alleviated a day after the medication (Table 3,4). By the time of discharge, decreased discomfort of sputum and increase of MMT was observed (Table 1, Fig. 3).

Table 3. Herbal Decoctions Prescribed During the Admission Period

\begin{tabular}{|c|c|}
\hline Herbal decoction & Name and amount $(\mathrm{g})$ of herbs \\
\hline $\begin{array}{l}\text { Modified } \\
\text { Chai Ling-tang } \\
\text { (柴苓湯 加味方) }\end{array}$ & $\begin{array}{l}\text { Lonicerae Flos, Forsythiae Fructus } 10 \mathrm{~g} \text { each / Bupleuri Radix } 8 \mathrm{~g} / \text { Alismatis } \\
\text { Rhizoma, Polyporus, White Poria, Pinelliae Praeparatum cum Zingiberis } 6 \mathrm{~g} \\
\text { each / Atractylodis Rhizoma Alba, Scutellariae Radix, Glycyrrhizae Radix, } \\
\text { Salt-water processed Phellodendri Cortex } 4 \mathrm{~g} \text { each / Jujubae Fructus, Zingiberis } \\
\text { Rhizoma Recens } 3 \mathrm{~g} \text { each / Cinnamomi Ramulus, Polygoni Avicularis Herba, } \\
\text { Dianthi Herba, Junci Medulla, Trichosanthis Semen, Armeniacae Semen } 2 \text { g each }\end{array}$ \\
\hline $\begin{array}{l}\text { Modified } \\
\text { Fen Xinqi-yin } \\
\text { (分心氣飲 加味方) }\end{array}$ & $\begin{array}{l}\text { White Poria } 6 \text { g / Notopterygii Rhizoma, Cinnamomi Ramulus, Akebiae Caulis, } \\
\text { Paeoniae Radix Alba, Mori Radicis Cortex, Citri Reticulatae Pericarpium, Citrii } \\
\text { Unshiu Immaturi Pericarpium } 4 \text { g each / Arecae Pericarpium, Junci Medulla, } \\
\text { Perilla Herba, Glycyrrhizae Radix Praeparata, Zingiberis Rhizoma Recens, Jujubae } \\
\text { Fructus } 3 \text { g each }\end{array}$ \\
\hline $\begin{array}{l}\text { Modified } \\
\text { Liu Wei Dihuang-tang } \\
\text { (六味地黃湯 加味方) }\end{array}$ & $\begin{array}{l}\text { Rehmanniae Radix Preparatm, Rehmanniae Radix Siccus, Lycii Fructus, Corni } \\
\text { Fructus } 8 \mathrm{~g} \text { each / Moutan Cortex, White Poria, Moutan Cortex } 6 \mathrm{~g} \text { each / } \\
\text { Polygoni Avicularis Herba, Pinelliae Praeparatum cum Zingiberis, Junci Medulla, } \\
\text { Dianthi Herba } 4 \mathrm{~g} \text { each }\end{array}$ \\
\hline $\begin{array}{l}\text { Modified } \\
\text { Jing Fang Di Huang-tang } \\
\text { (荊防地黄湯 加味方) }\end{array}$ & $\begin{array}{l}\text { Corni Fructus, Alismatis Rhizoma, White Poria } 8 \text { g each / Rehmanniae Radix } \\
\text { Preparat } 6 \text { g / Notopterygii Rhizoma, Angelicae Pubescentis Radix, Saposhnikovia } \\
\text { Radix, Plantaginis Semen, Schizonepetae Spica, Polygoni Avicularis Herba, Junci } \\
\text { Medulla, Dianthi Herba, Pinelliae Praeparatum cum Zingiberis } 4 \text { g each }\end{array}$ \\
\hline $\begin{array}{l}\text { Modified } \\
\text { Bu Yang Huan Wu-tang } \\
\quad \text { (補陽還五湯 加味方) }\end{array}$ & $\begin{array}{l}\text { Astragali Radix } 20 \text { g / Angelicae Gigantis Radix } 8 \text { g / Paeoniae Radix Rubra } 6 \text { g } \\
\text { / Persicae Semen, Cnidii Rhizoma, Carthami Flos, Notopterygii Rhizoma, Angelicae } \\
\text { Pubescentis Radix, Atractylodis Rhizoma Alba, Pinelliae Praeparatum cum Zingiberis } \\
4 \text { g each / Achyranthis Radix, White Poria, Polygoni Avicularis Herba, Dianthi } \\
\text { Herba, Alismatis Rhizoma, Eucommiae Cortex } 3 \text { g each }\end{array}$ \\
\hline
\end{tabular}


Bilateral Medial Medullary Infarction (Dejerene Syndrome) Patient Suffering from Quadriplegia

Treated by Korean Traditional Medicine: a Case Report

Table 4. The Prescription of Herbal Decoction and Change of Symptoms by Date

\begin{tabular}{|c|c|c|}
\hline $\begin{array}{l}\text { Prescribed } \\
\text { date }\end{array}$ & Herbal decoction & Change of symptoms \\
\hline $\begin{array}{c}\text { Day } 1 \\
\text {-day } 6\end{array}$ & $\begin{array}{l}\text { Modified Chai Ling-tang } \\
\text { (柴苓湯 加味方) }\end{array}$ & \\
\hline $\begin{array}{c}\text { Day } 7 \\
\text {-day } 12\end{array}$ & $\begin{array}{l}\text { Modified Fen Xinqi-yin } \\
\text { (分心氣飲 加味方) }\end{array}$ & Day 7 : increase of MMT. \\
\hline $\begin{array}{r}\text { Day } 13 \\
\text {-day } 31 \\
\end{array}$ & $\begin{array}{c}\text { Modified Chai Ling-tang } \\
\text { (柴苓湯 加味方 })\end{array}$ & $\begin{array}{l}\text { Day } 16: \text { alleviation of limb pain, decreased discomfort of sputum. } \\
\text { Day } 30: \text { alleviation of limb pain, decreased discomfort of sputum. }\end{array}$ \\
\hline $\begin{array}{c}\text { Day } 32 \\
\text {-day } 42 \\
\end{array}$ & $\begin{array}{l}\text { Modified Liu Wei Dihuang-tang } \\
\text { (六味地黃湯 加味方) }\end{array}$ & Day 39 : increase of MMT. \\
\hline $\begin{array}{c}\text { Day } 43 \\
\text {-day } 49\end{array}$ & $\begin{array}{l}\text { Modified Jing Fang Di Huang-tang } \\
\text { (荊防地黃湯 加味方) }\end{array}$ & Day 44: decreased discomfort of sputum. \\
\hline $\begin{array}{r}\text { Day } 50 \\
\text {-day } 52 \\
\end{array}$ & $\begin{array}{l}\text { Modified Bu Yang Huan Wu-tang } \\
\text { (補陽還五湯 加味方) }\end{array}$ & \\
\hline $\begin{array}{r}\text { Day } 53 \\
\text {-day } 59 \\
\end{array}$ & $\begin{array}{l}\text { Modified Chai Ling-tang } \\
\text { (柴苓湯 加味方) }\end{array}$ & \\
\hline $\begin{array}{l}\text { Day } 60 \\
\text {-day } 95\end{array}$ & $\begin{array}{l}\text { Modified Bu Yang Huan Wu-tang } \\
\quad \text { (補陽還五湯 加味方) }\end{array}$ & $\begin{array}{l}\text { Day 60: increase of MMT. } \\
\text { Day } 72: \text { alleviation of limb pain. } \\
\text { Day } 85: \text { increase of MMT. } \\
\text { Day } 86: \text { decreased discomfort of sputum. }\end{array}$ \\
\hline $\begin{array}{c}\text { Day } 96 \\
\text {-day } 120\end{array}$ & $\begin{array}{l}\text { Modified Jing Fang Di Huang-tang } \\
\text { (荊防地黃湯 加味方) }\end{array}$ & \\
\hline $\begin{array}{r}\text { Day } 121 \\
\text {-day } 126 \\
\end{array}$ & $\begin{array}{c}\text { Modified Chai Ling-tang } \\
(\text { 柴苓湯 加味方 })\end{array}$ & Day 126 : increase of MMT, decreased discomfort of sputum. \\
\hline
\end{tabular}

\section{Discussion}

Medial medullary infarction seldom occurs ${ }^{8}$, but it presents severe symptoms with only a small lesion'. Medial part of medulla oblongata contains pyramidal tract, medial longitudinal fasciculus, tectospinal tract, medial lemniscus and hypoglossal nerve ${ }^{4}$. It causes ipsilateral tongue weakness, leading to deviation to the infarction side, contralateral limb weakness, and contralateral loss of vibration, proprioception and discriminative touch ${ }^{2.10}$. In our case, quadriplegia can be explained by damage in both pyramidal tract, loss of proprioception as damage of medial lemniscus. Dysphagia and lingual palsy are suspected as result of hypoglossal nerve damage ${ }^{11}$.

In TKM terms, quadriplegia is categorized as wei zheng (瘘證), which can be explained as lung heat injury (肺熱傷津), liver and kidney deficiency (肝腎雐虛), weak spleen and stomach (脾胃虛弱), and blood stasis (疼阻脈絡) ${ }^{1}$. Also, stroke is categorized as fire-heat (火熱), yin-deficiency (陰虛), qi-deficiency (氣虛), dampness-phlegm（濕痰） and blood-stasis (瘀血) pattern ${ }^{12}$. On admission, the patient had mild fever, tachycardia (脈滑數) and dysuria（小 便赤涉). He also complained of dry mouth and had reddish-tip of tongue, so we diagnosed him as fire-heat (火熱) and lung-heat injury（肺熱傷津） pattern. Considering foley catheter insertion state, WBC increase in blood and urine also suggested 
the urinary tract infection (UTI). We prescribed him modified Chai Ling-tang (柴苓湯 加減方) and modified Fen Xinqi-yin (分心氣飲 加減方). Chai Ling-tang (柴苓湯) is introduced in 《dan xi xin fa (丹溪心法)》, which make balance the ban biao ban li (牛表牛裏) condition, copes with fever, tachycardia, dry-mouth and diarrhea. Several herbs were added considering the infectious state. Lonicerae flos (連趣) and forsythiaefructus (金銀花) were added for antibiotic effect. Polygoni avicularis herba (萹 蓄), dianthi herba (篗麥), junci medulla (燈心) were supplemented to treat dysuria and salt-water processed phellodendri cortex (黃柏) to focus on symptoms of urinary system. Also, trichosanthis semen (瓜萣仁) and armeniacae semen (杏仁) were added to alleviate dyspnea and sputum. Fen Xinqi-yin (分心氣飲) is introduced in 《shi yi de xiao fang (世醫得效防)》, which relaxes qi-stagnation and cardiac load ${ }^{13}$. Considering UTI, the dose of white poria (白获笭) was increased. As the vital signs started to keep stability, the patient was prescribed with modified Liu Wei Dihuang-tang (六味地黃湯 加味方) and Modified Jing Fang Di Huang-tang (荊防地黃湯 加味方). They both are usually prescribed to treat deficiency state of stroke. Notopterygii rhizome (姜活) and angelicae pubescentis radix (獨活) were supplemented to relax limb pain. Polygonia vicularis herba (萹蓄), dianthi herba (翟麥), junci medulla（燈心） were added to alleviate dysuria ${ }^{13}$. As the symptoms of fire-heat (火熱), such as discomfort of sputum, has relieved and considering long-term state of quadriplegia and limb pain, we diagnosed him as blood-stagnation and prescribed him modified $\mathrm{Bu}$ Yang Huan Wu-tang (補陽還五湯 加味方). Bu Yang Huan Wu-tang (補陽還五湯), is introduced in 《Yi lin gai cuo (醫林改錯)》 to manage cardio- cerebrovascular disease related with qi-deficiency and blood-stasis state. Son et $\mathrm{al}^{14}$ had revealed neuroprotective, angiogenic and anti-inflammatory effects in ischemic brains. Notopterygii rhizome (姜 活), angelicae pubescentis radix (獨活), Achyranthis Radix (牛膝) and Eucommiae Cortex (杜冲) were added to help relieve painful state. Also, resent systematic review revealed significant effect of EA treatment reducing post-stroke spasticity ${ }^{15}$. We insist it has contributed to alleviate spastic pain, which was $80 \%$ reduced.

On the second day of TKM treatment, the muscle power started to strengthen. From quadriplegia of MMT 1, muscle power of both upper extremity increased to MMT 3, both lower extremity to MMT 2 by discharge. The NIHSS scored 6 less points after treatment. It is also meaningful that the tracheal tube was removed, which means improvement in respiratory loss.

Among brain infarction, those owing to medial medullary lesion are very unusual and mostly show bad prognosis ${ }^{9}$. It is notable that our patient had improvement in quadriparesis, respiratory defects and sensory loss, after been treated with TKM. According to previous report of medullary infarction prognosis, it required at least 1 year to make partial recovery ${ }^{6,816}$. It is notable that the symptom of our patient made recovery in less than five months. However, there are some limitations that we can't identify which treatment has affected the most in alleviation of the symptoms, because the prescriptions of herbal decoctions had changed frequently and many kinds of treatments had been done simultaneously. More studies are required to evaluate the effect of TKM treatment of medial medullary infarction. 
Bilateral Medial Medullary Infarction (Dejerene Syndrome) Patient Suffering from Quadriplegia

Treated by Korean Traditional Medicine: a Case Report

\section{References}

1. Department of Cardiology \& Neurology of Korean Medicine College. Korean medicine of Cardiology \& Neurology. 4th rev. Seoul: Koonja books; 2013, p. 463-78.

2. Korean Neurological Association. Neurology. 3rd rev. Seoul: Panmun education; 2017, p. 645-98.

3. Korean stroke society. STROKE. 2nd rev. Seoul: Panmun education; 2015, p. 87-97.

4. Martin JH. Neuroanatomy. 4th rev. Seoul: Panmun education; 2014, p. 43-4.

5. Cho KI, Han MA, Lee JY, Choi JY, Kim DW. Case about Brainstem Infarction-Dejerine's syndrome and Wallenburg's syndrome. Korean Journal of Oriental Physiology \& Pathology 2002;16(6):1294-5.

6. Jitphapa P, Pongmoragot J, Parthasarathy S, Gustavo S. Bilateral Medial Medullary Infarction: A Systematic Review. Journal of Stroke and Cerebrovascular Diseases 2013;22(6):775-80.

7. Jang HW, Byun WM. Bilateral Medial Medullary Infarction Demonstrated by Diffusion-Weighted Imaging: Case Report. Yeungnam Univ JMed 2009:26(1):70-3.

8. Kim KS, Lee HS, Jung YH, Kim YD, Nam HS, Nam CM et al. Mechanism of Medullary Infarction Based on Arterial Territory Involvement. Journal of Clinical Neurology 2012;8(2):116-22.

9. Shono Y, Koga M, Toyoda K, Matsuoka H, Yokota C, Uehara T, et al. Medial Medullary Infarction Identified by Diffusion-Weighted Magnetic Resonance Imaging. Cerebrovascular Diseases 2010;
30(5):519-24.

10. Dejerine J. Sémiologie des affections du système nerveux. Paris: Masson; 1914.

11. Domenico R, Restivo DA, Hamdy S. Pharyngeal electrical stimulation device for the treatment of neurogenic dysphagia: technology update. Medical Devices 2018;11:21-6.

12. Lee JS KB, Ko MM, Kim JC, Oh DS, Kim NS, et al. Discriminant Model for Pattern Identifications in Stroke Patients Based on Pattern Diagnosis Processed by Oriental Physicians. Korean Journal of Oriental Physiology \& Pathology 2009:23(6):1460-4.

13. Hwang DY. Bang-Yak-Hap-Pyeon. 1st rev. Seoul: Younglimsa; 2010, p. 66-380.

14. Son HY, Park YK. Neuroprotective effect of modified Boyanghwano-Tang and the major medicinal plants, Astragali Radix and Salviae Miltiorrhizae Radix on ischemic stroke in rats. The Korea Journal of Herbology 2010;25(2) :71-9.

15. Cai Y, Zhang CS, Liu S, Wen Z, Zhang AL, Guo X, et al. Electroacupuncture for Poststroke Spasticity: A Systematic Review and MetaAnalysis. Archives of Physical Medicine and Rehabilitation 2017;98(12):2578-89.

16. Graf KJ, Pessin MS, DeWitt LD, Caplan LR. Proximal intracranial territory posterior circulation infarcts in the New England Medical Center Posterior Circulation Registry. European Neurology 1997:37(3) :157-68. 